Sun, X. M., H. HAN and X. S. WANG (2009): The relation between endogenous hormone contents and rooting of Larix kaempferi cuttings at different donor ages. Plant Physiology Communications 45(3): 217-222 (in Chinese with English abstract).

Sun, X. M., S. G. Zhang, X. S. Wang, L. W. QI and W. Y. WANG (2008): Genetic variation on rooting ability of stem cutting and juvenile growth of Larix kaempferi $\times$ L. olgensis interspecific hybrids. Scientia Silvae Sinicae 44(4): 41-47 (in Chinese with English abstract).

TANimoto, E. (2005): Regulation of root growth by plant hormones-roles for auxin and gibberellin. Plant Sciences 24(4): 249-265.

TANG, W. and Z. GUO (2001): In vitro propagation of loblolly pine via direct somatic organogenesis from mature cotyledons and hypocotyls. Plant Growth Regulation 33(1): 25-31.

Tonon, G., C. Kevers and T. Gaspar (2001): Changes in polyamines, auxins and peroxidase activity during in vitro rooting of Fraxinus angustifolia shoots: an auxinindependent rooting model. Tree Physiology 21: 655-663.

VAN DeR KRIEken, W. M., H. BReteler and M. H. M. VISSER (1992): The effect of conversion of indolebutyric acid into indoleacetic acid on root formation. Plant Cell Physiology 33: 709-713.

Van Der Krieken, W. M., H. Breteler, M. H. M. Visser and D. MAVRIDOU (1993): The role of the conversion of
IBA into IAA on root generation in apple: introduction of a test system. Plant Cell Reproduction 12: 203-206.

Villordon, Q. A., R. D. La Bonte, N. Firon, Y. KFIR and E. Pressman (2009): Characterization of adventitious root development in sweetpotato. HortScience 44: 651-655.

Wang, F., F. M. Cheng and G. P. Zhang (2006): The relationship between grain filling and hormone content as affected by genotype and source-sink relation. Plant Growth Regul 49: 1-8.

WeIJERS, D. and G. Jürgens (2004): Funneling auxin action: specificity in signal transduction. Curr Opin Plant Biol 7: 687-693.

WoODWARD, A. W. and B. BARTEL (2005): Auxin:regulation, antion, and interaction. Ann Bot (Lond) 95: 707-735.

YANG, J., J. ZHANG, Z. WANG, Q. ZHU and L. LIU (2001a): Water deficit-induced senescence and its relationship to the remobilization of pre-stored carbon in wheat during grain filling. Agron J 93: 196-206.

Zhang, H. G., C. L. Zhang, S. B. LAN, Y. K. Kang and B. L. PAN (2005): The analysis and selection for families of hybrid larch. Journal of Nanjing Forestry University (Natural Sciences Edition) 29(3): 69-72 (in Chinese with English abstract).

Zimmerman, P. W. and F. Wilcoxon (1935): Several chemical growth substances which cause initiation of roots and other responsesin plants. Contributions of the Boyce Thompson Institute 7: 209-229.

\title{
Primer Note: A novel set of EST-SSR markers in Tamarix: a resource to characterize this genus
}

\author{
By S. Terzoli ${ }^{1)}$, E. Cattan ${ }^{2)}$, M. Sabatti ${ }^{1)}$, R. VAlentini $^{1), 3)}$, A. Zilberstain ${ }^{2)}$ and E. Kuzminsky ${ }^{\left.1),{ }^{*}\right)}$
}

(Received 22 ${ }^{\text {th }}$ June 2012)

\begin{abstract}
Both the negative and positive ecological impact of Tamarix plants is controversial, and thus a more comprehensive understanding is necessary. Tamarisks are

1) Department for Innovation In Biological, Agro-food and Forest systems, University of Tuscia, via S. Camillo de Lellis snc. I-01100 Viterbo, Italy.

$\left.{ }^{2}\right)$ Department of Molecular Biology and Ecology of Plants, Tel Aviv University, Tel Aviv, 69978, Israel.

$\left.{ }^{3}\right)$ Euromediterranean Center for Climate Change (CMCC), Division Climate Change Impacts on Agriculture, Forests and Natural Ecosystems, Via Augusto Imperatore 16, 73100 Lecce, Italy.

*) Corresponding Author: Elena KuZminsky. DIBAF (Department for Innovation in Biological, Agro-food and Forest systems) - University of Tuscia, Via San Camillo de Lellis, I-01100 Viterbo, Italy. Tel: +39-0761-357249; Fax: +39-0761357389. E-Mail: elkuz@unitus.it.
\end{abstract}

invasive in many countries but the inter-specific transferability that characterizes simple sequence repeats (SSRs) could be harnessed to track the spread of specific genotypes or to study invasive populations. Thirteen polymorphic SSR markers, derived from expressed sequence tag (EST), were identified by first screening 26 samples of $T$. aphylla, T. jordanis, T. nilotica, and T. tetragyna and then 33 unidentified tamarisks from Yotvata, Israel. The mean number of alleles per locus ranged from two to 14 and the mean expected heterozygosity was 0.415. These EST-SSR markers will undoubtedly be useful in the genetic characterization of the genus Tamarix due to their high cross-species transferability which enables the estimation of the genetic diversity among and within different species, that are adapted to the same desert habitat under severe environmental constraints.

Key words: Tamarisk; species identification; microsatellite; Bayesian assignment method. 


\section{Introduction}

The genus Tamarix is native to Europe, North Africa, and Central Asia and has recently gained attention for its extreme tolerance to abiotic stresses. Tamarix species are widespread in arid and semi-arid areas in the Mediterranean Basin. The species T. aphylla L. Karst., T. jordanis Boiss., T. nilotica Ehrenb. Bge, and T. tetragyna Ehrenb. are desert halophyte native to the Middle East, which is the second centre of differentiation of the genus (BAUM, 1978). These species have been proven to be used as a new source for energy crops since they maintain high biomass production even when growing under extreme environmental conditions (EsHEL et al., 2011). Since its introduction over the past century in North, South America, and Australia, the genus Tamarix has been viewed in a negative light by progressively becoming an invasive plant negative and damaging environment in riparian habitats (GASKIN and SCHAAL, 2003). In the United States, for example, millions of dollars are spent every year to control and attempt to eradicate tamarisk, and ongoing studies on biological control agents require a better understanding the identity of the invasive species (GASKIN, 2003). However, despite this negative attention, some authors advocate more in-depth studies (STROMBERG et al., 2009; DAVIs et al., 2011), since the invasive ability of Tamarix, indicates its success, combating potential, in different climate and ecological conditions.

The taxonomy of this genus is one of the most difficult among Angiosperms to accurately map. In its latest revision, BAUM (1978) recognized 54 species based on morphological traits of the floral disk; a trait that is difficult to observe and not always available. Furthermore, GASKIN and SCHAAL (2003) found that sometimes floral disk traits could be misleading as a means of identifying specimens. Nonetheless, molecular markers are an innovative tool that could better enable species identification, and SSRs are the most promising class of molecular markers employed for phylogenetic studies (KALIA et al., 2011). Despite the fact that the use of SSR markers is time-consuming and expensive for development (ELLIS and BURKE, 2007), the screening of an available sequence database and the transferability of markers from related species offer an alternative method of discovering SSRs in species that have yet to be investigated.

The hypervariability, multi-allelism, codominant inheritance, abundance and genome coverage, that characterize SSR markers could assess and describe the structure of genetic diversity in homogeneous groups, which in some cases may be indicative of species (Duminil et al., 2006). The effectiveness of this approach has recently been improved by the combination of informative markers with powerful statistical inference methods, such as Bayesian clustering models (PRITCHARD et al., 2000), which use genotypic data to provide a posterior estimation of the existing genetic structure. A total of 22713 ESTs, derived from T. hispida Willd., T. androssowii Litv., T. ramosissima Ledeb., and T. albiflonum M. T. Liu, are currently recorded on the NCBI database. These sequences were assembled and screened to develop EST-SSRs in T. africana (TERZOLI et al., 2010). The scarcity of genetic resources and the increasing interest in Tamarix determine the requirement for more available molecular markers for the scientific community. In this present work, 22 unpublished SSRs that were monomorphic, or not conserved in T. africana, were tested for cross-species amplification in T. aphylla, T. jordanis, T. nilotica, and T. tetragyna.

The aim of this study was to estimate genetic diversity among and within species that are adapted to extreme environmental conditions and are grown in the same desert habitats. Additional markers could enable genetic characterization of Tamarix biodiversity that is required for the selection of stress tolerant genotypes, the protection, and the management of natural resources.

\section{Materials and Methods}

\section{Plant materials}

Polymorphism and cross-species amplification were evaluated on a group of 26 vouchered samples collected in different tamarisk stands in Israel (T. aphylla 11 plants, T. jordanis six plants, T. nilotica seven plants, and T. tetragyna two plants). In addition, 33 unidentified tamarisks from the Yotvata stands were analyzed to further assess markers. The undefined ecotypes found in Yotvata could represent the local Tamarix ecotype population, since they germinated spontaneously within an experimental plot. A very limited number of ecotypes, identified as T. tetragyna, were found in our search for local Tamarix species. However, even this small data set was included to test for cross-species amplification, by comparing two examples collected from different places in the desert margins. DNA extractions were performed using the DNeasy Mini Plant kit (QIAGEN) following the manufacturers' protocol.

\section{PCR amplification and EST-SSRs analysis}

Polymerase chain reaction was performed by a duplex PCR in $12.5 \mu \mathrm{l}$ reaction volume under the conditions specified in the Type-it microsatellite multiplex kit (QIAGEN) and using 1X reaction Buffer. A 19-bp M13 tail (5'-CACGACGTTGTAAAACGAC-3') was added to the 5' end of all the forward primers. In the reaction $0.08 \mu \mathrm{M}$ of the two forward M13 5'-tail-end primers, $0.1 \mu \mathrm{M}$ of the two reverse primers, $0.1 \mu \mathrm{M}$ of labelled 6-fam or VIC M13 primer were added to the mix. Samples were amplified with the following thermal protocol: 5 min of denaturation at $95^{\circ} \mathrm{C}$, followed by 7 cycles at $94^{\circ} \mathrm{C}$ for $30 \mathrm{~s}$, annealing temperature $1 \mathrm{~min}$ and $30 \mathrm{~s}$, extension at $72^{\circ} \mathrm{C}$ for $30 \mathrm{~s} ; 24$ cycles at $94^{\circ} \mathrm{C}$ for $30 \mathrm{~s}$, $51^{\circ} \mathrm{C}$ for $1 \mathrm{~min}$ and $30 \mathrm{~s}, 72^{\circ} \mathrm{C}$ for $30 \mathrm{~s}$; and one step at $60^{\circ} \mathrm{C}$ for $30 \mathrm{~min}$. Each reaction was performed with 10ng of DNA template. The PCR products were diluted up to 1:40, and were separated by capillary electrophoresis with a 500 bp size standard (ROX 500, Applied Biosystems) using an ABI Prism 3700 (Applied Biosystems) automatic sequencer.

\section{EST-SSRs characterization}

Population genetics parameters for the 13 polymorphic loci were estimated by using GenAlEx 6.4 software 
(PeAkAl and Smouse, 2006) per species. Tests for HardyWeinberg equilibrium and linkage disequilibrium were calculated using GenePop 4.0.10 (RAYMOND and RusseT, 1995). The statistical significance of the results adopted the following parameters: 10000 dememorization, 100 batches and 10000 iterations per batch. The significance level for multiple tests was adjusted by the sequential Bonferroni method (RICE, 1989).

Amplicons of polymorphic SSRs of T. jordanis were sequenced to allow for the assignment of putative homology to known genes and for submission in the GenBank. Amplicons were purified by using Qiaquick PCR purification kit (QIAGEN). The purified products were quantified in a Qubit fluorometer (Invitrogen) following the manufacturers instructions. Successively $30 \mathrm{ng}$ of the purified product was added to two $1.5 \mathrm{ml}$ tubes, $15 \mathrm{pM}$ of both the forward and the reverse primers was added alternatively in each tube. The tubes containing the solution with purified amplicons and the primers were shipped to Eurofins MWG Operon (M-Medical) for a value read sequencing service. The sequences were searched against the GenBank nonredundant database using BLASTX (ALTSCHUL et al., 1997) for functional annotation with the expected value $<10^{-7}$.

\section{Species assignment}

A Bayesian clustering method, implemented in STRUCTURE 2.3.3 (PRITCHARD et al., 2000), was used to assign the unidentified individuals to genetic clusters that may correspond to species identity. The length of the burn-in period and the number of Markov chain Monte Carlo were set to 100000 and 100000 repetitions; and the option "correlated alleles frequencies model" for ancestry was chosen. Two analyses were performed on the whole set of individuals; the first without assuming any predefined structure. In the second analysis the USEPOPINFO model was used to allow the ancestry estimation of the unidentified individuals, excluding the two vouchered $T$. tetragyna. The POPFLAG $=1$ option was set for the complex of plants identified by morphological traits, while, the POPFLAG $=0$ option was set for the unidentified individuals. The number of clusters $\mathrm{K}$ was tested in the range of 1 to 9 with 10 iterations for each value of $K$. The $K$ clusters were inferred by minimizing Hardy-Weinberg and linkage disequilibrium within clusters. All sampled individuals were assigned probabilistically to clusters. The true number of $\mathrm{K}$ was estimated according to an ad hoc quantity based on the second order rate of change of the likelihood function with respect to $K(\Delta K)$ (EvanNo et al., 2005).

\section{Results and Discussion}

Thirteen EST-SSRs showed transferable and polymorphic results among the tested species. The range of transferability of EST-SSRs observed in this work was consistent with values reported in scientific papers, which assessed a range of $60-80 \%$ of transferability for these kind of markers (ELLIS and BuRKE, 2007). The observed number of alleles, considering all the analyzed samples, (vouchered and unidentified), ranged from four to 14 with an average of 8.54 alleles per locus which was the highest value compared to other SSR loci in Tamarix (GASKIN et al., 2006; TERZOLI et al., 2010). It is worth noting that the present work concentrates on four differ-

Table 1. - Initial primer screening in Tamarix species. Number of observed alleles (Na), Number of effective alleles $(\mathrm{Ne})$, observed heterozygosity $(\mathrm{Ho})$, and expected heterozygosity $(\mathrm{He})$ per locus for each species determined by genotyping only vouchered samples.

\begin{tabular}{|c|c|c|c|c|c|c|c|c|c|c|c|c|c|c|c|c|}
\hline \multirow[b]{2}{*}{ Lacus } & \multicolumn{4}{|c|}{ T. aphylla } & \multicolumn{4}{|c|}{$T$ jordanis } & \multicolumn{4}{|c|}{ T. nilotica } & \multicolumn{4}{|c|}{ T. terragina } \\
\hline & $V_{a 1}$ & Ve & Ho & $\mathrm{He}$ & $\mathrm{Na}$ & $\mathrm{Ve}$ & $\mathrm{Ho}_{\mathrm{o}}$ & $\mathrm{He}$ & Nat & Ne & $\mathrm{Ho}$ & $\mathrm{He}$ & $\mathrm{Na}$ & Ve & $\mathrm{H} v$ & $\mathrm{He}$ \\
\hline Th69 & 2 & 1.60 & 0.50 & 0.38 & 3 & 2.67 & 0.67 & 0.63 & 2 & 1,60 & 0.17 & 0.38 & 3 & 2.67 & 1.00 & 0.63 \\
\hline Ta139 & [ & 1.00 & 0.00 & 0.60 & 1 & 1.00 & 0.00 & 0.00 & 1 & 1.00 & 0.00 & 0.00 & 2 & 2.00 & 0.00 & 0.50 \\
\hline Th320 & 1 & 1.00 & 0.000 & 0.00 & 2 & 1.38 & 0.00 & 0.28 & 4 & 3.60 & 0.00 & 0.72 & 1 & 1.00 & 0.60 & 0.00 \\
\hline Th5333 & 1 & 1.00 & 0.00 & 0.00 & l & 1.00 & 0.00 & 0.00 & 2 & 1.15 & 0.14 & 0.13 & 2 & 1.60 & 0.50 & 0.38 \\
\hline Thl一69 & I & 1.00 & 0.00 & 0.00 & 2 & 1.18 & 0.17 & 0.15 & 3 & 1.81 & 0.29 & 0.45 & 2 & 2.00 & 1.00 & 0.50 \\
\hline Th7 723 & I & 1.00 & 0.000 & 0.190 & 3 & 2.67 & 0.67 & 0.63 & 6 & 4.00 & 1.00 & 0.75 & 1 & 1.00 & 0.00 & 0.000 \\
\hline Th1 1239 & 0 & 0.00 & 0.00 & 0.00 & 6 & 3.27 & 1.00 & 0.69 & 4 & 2.97 & 0.43 & 0.66 & 3 & 2.67 & 1.00 & 0.63 \\
\hline$T h 1286$ & [ & 1.00 & 0.00 & 0.00 & 5 & 2.12 & 0.50 & 0.53 & 4 & 2.51 & 0.86 & 0.60 & 2 & 2.00 & 1.00 & 0.50 \\
\hline Thl 1420 & I & 1.00 & 0.00 & 0.00 & 4 & 2.88 & 0.33 & 0.65 & 6 & 4.90 & 0.57 & 0.80 & 2 & 2.00 & 0.00 & 0.50 \\
\hline Ta1456 & 1 & 1.00 & 0.00 & 0.00 & 2 & 1.38 & 0.00 & 0.28 & 1 & 1.00 & 0.00 & 0.00 & 2 & 1.60 & 0.50 & 0.38 \\
\hline Th2287 & 2 & 1.10 & 0.09 & 0.09 & 4 & 2.88 & 0.83 & 0.65 & 5 & 3.77 & 0.57 & 0.73 & 2 & 1.60 & 0.50 & 0.38 \\
\hline$T / 1.3496$ & 3 & 2.18 & 3.000 & 0.54 & 5 & 3.13 & 0.83 & 0.68 & 3 & 2.32 & 0.33 & 0.57 & 2 & 1.60 & 0.50 & 0.38 \\
\hline Th3498 & 1 & 1.00 & 0.00 & 0.00 & 3 & 1.52 & 0.20 & 0.34 & 6 & 4.80 & 0.67 & 0.79 & 2 & 1.60 & 0.50 & 0.38 \\
\hline
\end{tabular}


ent species, thus the high average number of alleles per locus could be due to this peculiarity. The characterization of our EST-SSRs considering only the vouchered samples is reported in Table 1.

After applying Bonferroni's correction, no locus deviated significantly from Hardy-Weinberg equilibrium $(\mathrm{P}<0.05)$, and no significant linkage disequilibrium $(\mathrm{P}<0.05)$ between locus pair was observed. On the con- trary, genomic SSRs described in GASKIN et al. (2006) displayed significant deviation from Hardy-Weinberg equilibrium, and in $47 \%$, locus pair significant linkage disequilibrium was observed.

Seven loci showed significant similarities to known genes or with proteins of unknown function (Table 2), thus our EST-SSRs could assess diversity for functional traits.

Table 2. - Characteristics of the 13 polymorphic EST-SSRs developed in Tamarix. Forward sequence (F), reverse sequence (R), repeated motif, GenBank accession number of T. jordanis loci, annealing temperature (Ta), allele size range including $19 \mathrm{bp}$ of M13-tail determined by genotyping both our vouchered and unidentified samples, total number of observed alleles (Na), and accession numbers of putative homology are illustrated.

\begin{tabular}{|c|c|c|c|c|c|c|c|}
\hline & Primer sequence & MOTIF & Accession & $\begin{array}{l}\mathrm{T}_{\mathrm{i}} \\
{ }^{\circ} \mathrm{C}\end{array}$ & $\begin{array}{l}\text { Range } \\
\text { Size } \\
\text { (bp) }\end{array}$ & Nia & Putative lomology \\
\hline Th69 & $\begin{array}{l}\text { F: GGCCCACATTTCACTACACC } \\
\text { R: TCCGCTCTTCTCCATGATCT }\end{array}$ & $(A A G)_{7}$ & HF611036 & 55 & $(113-134)$ & 9 & $\mathrm{ADQ} 91847.1$ \\
\hline lal 39 & $\begin{array}{l}\text { I:AIGCAICACAAAGCICGAIG } \\
\text { R: TCTTTTGGT NGCTGCGAAGG }\end{array}$ & $(\mathrm{GGAI})_{5}$ & HL6]1037 & 58 & $(175-187)$ & 4 & $\triangle O N L$ \\
\hline Th320 & $\begin{array}{l}\text { F:GCGCACACACATACACACAN } \\
\text { R:TTGGGCAGGATAAGGGTATG }\end{array}$ & $(\mathrm{GTTT})_{4}$ & IIE611038 & 54 & $(132-152)$ & 6 & IONE \\
\hline$T h 533$ & $\begin{array}{l}\text { F:GAGAAGGGIGGLATGGGTCA } \\
\text { R: 'I"IICAGCAGICGIIGIACGO }\end{array}$ & $(C A C)_{5}$ & $\mathrm{HI} 611039$ & 55 & $(1.30-1.39)$ & 5 & I:AY78054.1 \\
\hline Th669 & $\begin{array}{l}\text { F: GGCACTTCCAGATTCCAAAA } \\
\text { R:GGTAGAAGCTCGGIGAGACG }\end{array}$ & $(\mathrm{TCC})_{3}$ & IIE611040 & 54 & $(126-138)$ & 4 & AAM954558.1 \\
\hline lh 723 & $\begin{array}{l}\text { I: AGGAGGGGGACAGCAMAA } \\
\text { R. CATGTCACTGCCTCTGCAAT }\end{array}$ & $(\mathrm{Cl})$ & $1[1: 61104]$ & 54 & $(194-265)$ & 10 & ACM78620I \\
\hline Th1239 & $\begin{array}{l}\text { F:AATGTGTCGGCACCGAGTAG } \\
\text { R: TICCICICICCAGCCAAACA }\end{array}$ & $(\mathrm{TGC})_{3}$ & HE611042 & 54 & $(187-211)$ & 9 & XONE \\
\hline Th1286 & $\begin{array}{l}\text { F:GGCCAGAGAGAGAACGAAGA } \\
\text { R:GCGTCACCAACTAACGATGA }\end{array}$ & $(G \wedge N)_{9}$ & HF6 11043 & 54 & $(121-151)$ & 9 & АDI39634. 1 \\
\hline $\operatorname{Th} 1420$ & $\begin{array}{l}\text { F: CACICICCCICICGITCGIC } \\
\text { R: TCTCTGCTTTTTCCGCTTTT }\end{array}$ & $(\mathrm{CCl})_{\mathrm{s}}$ & HE6] 1044 & 55 & $(218-244)$ & 11 & YONE \\
\hline Ta1456 & $\begin{array}{l}\text { F: CCCTCACTCCAACCANAAAC } \\
\text { R: TGACGAGCOCTAGCTATCTG }\end{array}$ & $(\text { АTTA })_{3}$ & $\operatorname{IIT} 611045$ & 54 & $(212-228)$ & 4 & XP_002269617.1 \\
\hline Th2287 & $\begin{array}{l}\text { F: GTCCGCATGCAGGIAAGG } \\
\text { R:CCICICICIGCAGACAACACC }\end{array}$ & $\left(A^{\prime}\left[T^{T}\right)_{6}\right.$ & HE6II046 & 54 & $(162-204)$ & 14 & SONE \\
\hline Th3496 & $\begin{array}{l}\text { F: GATCTTGGTCAGGTGGGTTG } \\
\text { R:TCGTCAGCAGGGAAАTAAGG }\end{array}$ & $(\mathrm{GAA})_{7}$ & І ІЕ611047 & 54 & $(216-237)$ & 12 & DAA06358.1 \\
\hline Th3498 & $\begin{array}{l}\text { F: GTGTCCGGGAATCATCIGIC } \\
\text { R:GGCCCCCAAAGTAAAACAIT }\end{array}$ & $\left(\mathrm{CC}_{10}\right.$ & HE611048 & 54 & $(230-284)$ & 14 & XONE \\
\hline
\end{tabular}


a

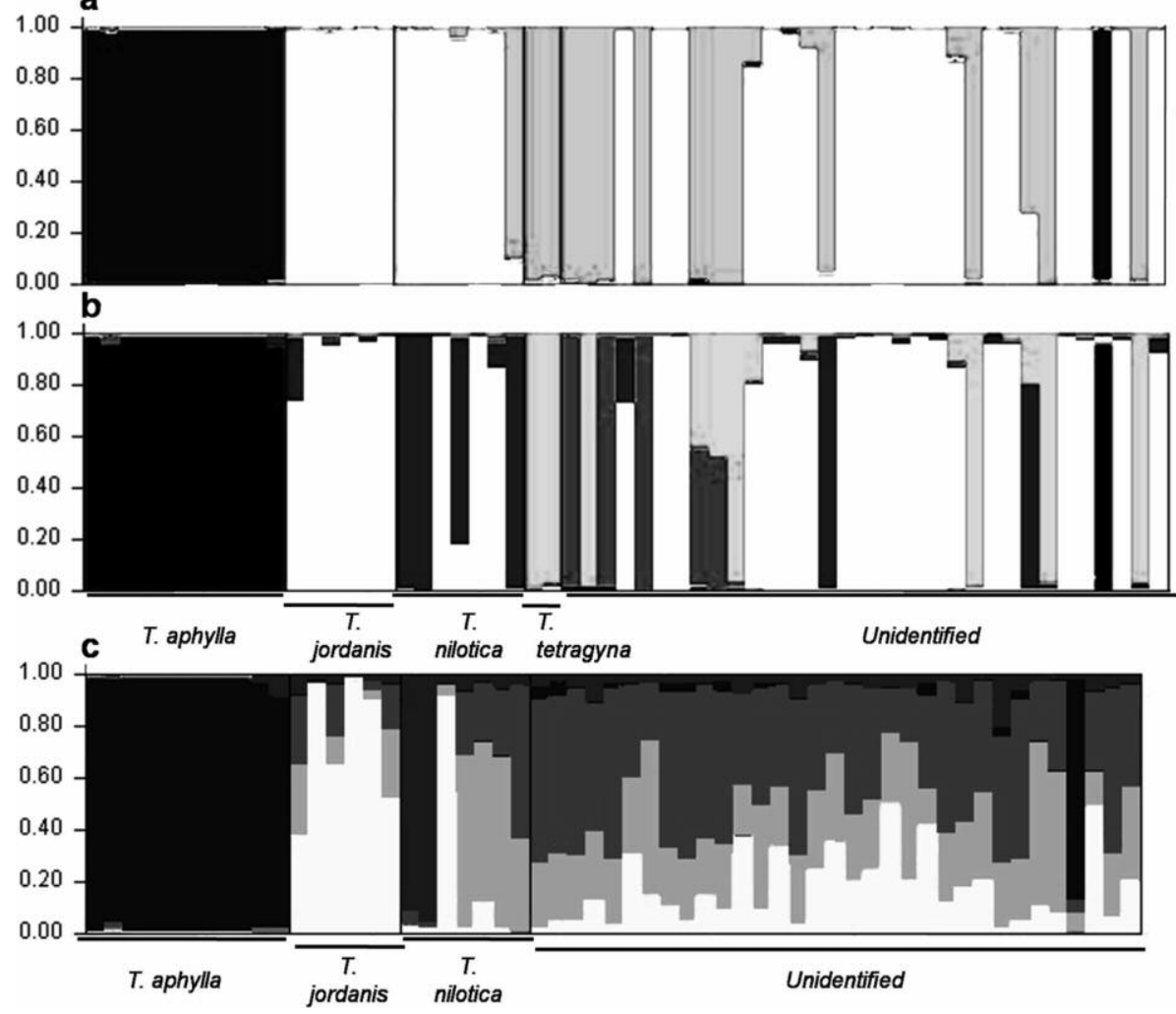

Figure 1. - The identity of individuals is represented as bar plots whose length are proportional to the individual genome membership in the cluster. (a) The identified plants were used to establish the connections with the inferred clusters: black bars correspond to T. aphylla, white bars correspond to T. jordanis and T. nilotica simultaneously, and light-gray bars correspond to T. tetragyna. (b) Individual cluster membership is according to the five clusters model: black bars represent $T$. aphylla, white bars correspond to T. jordanis, dark-gray bars correspond to T. nilotica, light-gray bars correspond to T. tetragyna, and grey bars correspond to an unknown species. (c) Individual cluster membership using the USEPOPINFO according to the five clusters model: black bars represent $T$. aphylla, three vouchered $T$. jordanis resulted assigned to cluster number two (white bars), two vouchered T. nilotica were assigned to cluster number three (darkgrey bars) and one to cluster number two, all the remaining samples resulted admixed.

A Bayesian clustering method (PRITCHARD et al., 2000) allowed the assignment of unidentified individuals to genetic clusters that may correspond to species identity. Vouchered samples displayed individuals collected in different populations, thus the Hardy-Weinberg expectation could be not satisfied. When the genetic divergence between species was high it was noted that the Bayesian method could tolerate deviations from the Hardy-Weinberg equilibrium (CORNUET et al., 1999). The posterior analysis of the likelihood function, according to EvANNo et al. (2005) for the analyses without any predefined structure, pointed out the existence of two distinctive peaks at $K=3$ and $K=5$. According to the model with three clusters, the species T. aphylla, T. jordanis, and T. tetragyna have a clear individual assignment, while the species $T$. nilotica grouped together with T. jordanis (Fig. 1a). The T. aphylla vouchered samples, had an average posterior probability of belonging to cluster one of 0.99 , whereas $T$. jordanis and T. nilotica samples were assigned to cluster number two with an average probability of 0.99 and 0.98 , respectively, and T. tetragyna samples were assigned to cluster number three with an average probability of 0.98 . By starting with a total of 33 unidentified plants from the Yotvata stand, the Bayesian approach assigned one individual to T. aphylla, 18 to the T. jordanis-nilotica group, while 11 were assigned to T. tetragyna. Then, three samples showed an assignment threshold lower than 0.9 and were considered to be admixed.

According to the five cluster model, the four species considered in the present study formed distinctive clusters, while the last cluster could identify individuals with further species ancestry (Fig. 1b). The T. aphylla vouchered samples had an average posterior probability of belonging to cluster one of $0.98, T$. jordanis samples were assigned to cluster two with an average probability of $0.94, T$. nilotica samples were assigned simultaneously to clusters number two (the same as T. jordanis) and three, with an average probability of 0.55 and 0.43 , respectively, whereas T. tetragyna individuals were assigned to cluster four with an average posterior probability of 0.98 . The Bayesian approach assigned the 33 unidentified plants from the Yotvata stand as following: one individual to T. aphylla, 17 to $T$. jordanis, one to T. nilotica while 5 were assigned to the T. tetragyna. Three samples were assigned to a fifth cluster which 
does not correspond with any of our investigated species. Six samples showed an assignment threshold lower than 0.9. A second analysis was performed taking into account the morphological identification of individuals according to the USEPOPINFO model. According to this model, the Ln $\mathrm{P}(\mathrm{D})$ function and $\Delta \mathrm{K}$ displayed patterns similar to the previous one with a mode at $\mathrm{K}=5$ (Fig. 1c) and all the T. aphylla individuals were assigned to cluster number one with an average probability of 0.96 , while three vouchered $T$. jordanis individuals were assigned to cluster number two; three resulted admixed, and two $T$. nilotica were assigned to cluster number three. Another was assigned to cluster number two, and the remaining three individuals resulted admixed. In this analysis no unidentified individual was assigned to a genetic cluster.

The partitioning of genetic clusters showed a clear assignment of vouchered T. aphylla individuals, but it was not same for T. jordanis and T. nilotica, whose individuals grouped together in the same cluster. The lack of a clear assignment for T. jordanis and T. nilotica could be due to the limited data set analyzed in the present study rather than to a putative introgression between these species, although introgression in Tamarix is well documented in literature (GASKIN and SCHAAL, 2003), and gene flow between introgressive species could lead to shared polymorphism (DRUMmOND and HAMILTON, 2007).

\section{Conclusions}

The natural capacity of Tamarix plants to survive in extreme environmental conditions could be harnessed to contrast desertification. On the other hand, some Tamarix specimens have become invasive in many countries worldwide where tamarisks are considered a threat. In Tamarix, these newly developed EST-SSRs could represent an additional resource in the genetic characterization of this genus, but even did in the tracking of the spread of invasive genotypes allowing matching of biological control agents.

\section{Acknowledgements}

This work was sponsored by the Italian-Israeli Cooperation on Environmental Research and Development Project "Harnessing the biodiversity of Mediterranean plants for mitigating the effect of climate change and desertification" by The Italian Ministry of Environment Land \& Sea. The first author is grateful to the University of Cordoba for its kind hospitality. A special thanks to TAMAR WEINBERG and the two anonymous reviewers for their comments on the first version of the manuscript and to PAULA CONNOLLY for the proof reading.

\section{References}

Altschul, S. F., T. L. Madden, A. A. Schaffer, J. Zhang, Z. Zhang, W. Miller and D. LipMan (1997): Gapped BLAST and PSI-BLAST: a new generation of protein database search programs. Nucleic Acids Research 25: 3389-3402.

BAuM, B. R. (1978): The genus Tamarix. Israel Academy of Science and Humanities, Jerusalem.
Cornuet, J. M., S. Piry, G. Luikart, A. Estoup and M. Solignac (1999): New methods employing multilocus genotypes to select or exclude populations as origins of individuals. Genetics 153: 1989-2000.

Davis, M. A., M. K. Chew, R. J. Hobbs, A. E. Lugo, J. J. Ewel, G. J. VermeiJ, J. H. Brown, M. L. Rosenzweig, M. R. Gardener, S. P. Carroll, K. Thompson, S. T. A. Pickett, J. C. Stromberg, P. Del Tredici, K. N. Suding, J. G. Ehrenfeld, J. Philip Grime, J. Mascaro and J. C. BRIGGS (2011): Don't judge species on their origins. Nature 474: 153-154.

Drummond, C. S. and M. B. HamiLton (2007): Hierarchical components of genetic variation at species boundary: population structure in two sympatric varieties of Lupinus microcarpus (Leguminosae). Molecular Ecology 16: 753-769.

Duminil, J., H. Caron, I. Scotti, S. O. Cazal and R. J. PETit (2006): Blind population genetics survey of tropical rainforest trees. Molecular Ecology 15: 3505-3513.

Ellis, J. R. and J. M. BuRKE (2007): EST-SSRs as a resource for population genetic analyses. Heredity 99: 125-132.

Eshel, A., I. Oren, C. Alekperov, T. Eilam and A. ZilberSTEIN (2011): Biomass production by desert halophytes: alleviating the pressure on scarce resources of arabe soil and fresh water. The European Journal of Plant Science and Biotechnology 5: 48-53.

Evanno, G., S. Regnaut and J. Goudet (2005): Detecting the number of clusters of individuals using the software STRUCTURE: a simulation study. Molecular Ecology 14: 2611-2620.

GASKIN, J. F. (2003): Molecular systematics and the control of invasive plants: A case study of Tamarix (Tamaricaceae). Annals of Missouri Botanical Garden 90: 109-118.

GASkin, J. F., A. E. Pepper and J. R. MANhart (2006): Isolation and characterization of 10 polymorphic microsatellites in saltcedars (Tamarix chinensis and Tamarix ramosissima). Molecular Ecology Notes 6: 1147-1149.

GASKIN, J. F. and B. A. ScHAAL (2003): Molecular phylogenetic investigation of U.S. invasive Tamarix. Systematic Botany 28: 86-95.

Kalia, R. K., M. K. Rai, S. Kaila, R. Singh and A. K. DHAWAN (2011): Microsatellites markers: an overview of the recent progress in plants. Euphytica 177: 309-334.

PeAKall, R. and P. E. SMouse (2006): GENALEX 6: genetic analysis in Excel. Population genetic software for teaching and research. Molecular Ecolology Notes 6: 288-295.

PRitchard, J. K., M. Stephens and P. Donnelly (2000): Inference of population structure using multilocus genotype data. Genetics 155: 945-959.

RAYMOND, M. and F. ROUSSET (1995): GENEPOP (version 1.2): population genetics software for exact tests and ecumenicism. Journal of Heredity 86: 248-249.

RICE, W. R. (1989): Analyzing tables of statistical tests. Evolution 43: 223-225.

Stromberg, J. C., M. K. Chew, P. L. Nagler and E. P. GLENN (2009): Changing perceptions of change: the role of scientists in Tamarix and river management. Restoration Ecology 17: 177-186.

Terzoli, S., I. Beritognolo, M. SABAtTi and E. KuZminsky (2010): Development of a novel set of EST-SSR markers and cross-species amplification in Tamarix africana (Tamaricaceae). American Journal of Botany 97: e45-e47. 